\title{
BENTUK DAN STRUKTUR PENYAJIAN TARI TINGANG NELISE PADA SUKU DAYAK BAHAU BUSANG SUB SUKU LONG GELAAT DI ULU MAHAKAM
}

\author{
Katarina Devung \\ Jurusan Tari Fakultas Seni Pertunjukan, \\ PSDKU Institut Seni Indonesia Yogyakarta Rintisan ISBI Kaltim \\ Email: Katarina6478@gmail.com
}

\section{RINGKASAN}

Tari Tingang Nelise merupakan tari tradisional yang berkembang di desa Long Tuyoq khususnya Sub Suku Long Gelaat. Tarian ini merupakan tarian rakyat yang dibawakan secara khusus pada saat acara Nemlaai, acara adat anak, pernikahan dan Dangai. Tari Tingang Nelise terinspirasi dari keseharian burung Enggang yang sedang merapikan bulunya, memperindah serta mempercantik dirinya. Tari Tingang Nelise adalah salah satu tarian yang memiliki banyak variasi dari tarian-tarian Karang Sapeq. Tingang Nelise awalnya dikenal dengan nama Tari Tingang Mate, namun karena itu memberikan makna yang kurang tepat terlebih lagi karena gerakannya lebih tepat disebut dengan Nelise (berhias). Penelitian ini akan mengupas bentuk dan struktur penyajian tari Tingang Nelise dilihat dari tari tradisional yang menggabungkan motif-motif dari setiap gerakan-gerakannya. Dengan pendekatan koreografi dan struktur. Pendekatan koreografi melihat tema, pelaku, gerak, rias busana, properti, musik iringan dilihat dari bentuk tariannya dibawakan sebagai tari hiburan atau rakyat yang tumbuh di kalangan masyarakat. Pendekatan struktur mengupas tari Tingang Nelise dilihat dari analisis struktural dimulai dari unsur gerak, frase gerak, kalimat gerak dan gugus gerak. Tari Tingang Nelise memiliki ciri khas yang terlihat dari motif-motif geraknya. Gerak yang paling dominan adalah kaki dan tangan. Secara struktur tari Tingang Nelise terbagi ke dalam 4 gugus, dan memiliki 7 motif gerak yang khas yaitu motif gerak Ngaset yang melompat ke kanan dan kiri dengan posisi jongkok, Nyebeb, Nyegung, Nyebib, Lemako, Nyelut, dan Nelise.

\section{Kata Kunci: Tingang Nelise, Dayak Bahau Busang, Long Gelaat}




\title{
ABSTRACT \\ FORM AND STRUCTURE OF PRESENTATION OF TINGANG NELISE DANCE IN DAYAK BAHAU BUSANG TRIBE LONG GELAAT TRIBE REGION IN ULU MAHAKAM
}

\author{
Katarina Devung \\ Email: Katarina6478@gmail.com
}

Tingang Nelise dance is a traditional dance of Dayak community, Long Gelaat tribe in Long Tuyoq village. This dance is a folk dance that is performed specifically at Nemlaai events, children's traditional events, weddings and Dangai. Tingang Nelise dance is inspired by the daily activities of hornbills that are grooming their feathers and beautifying themselves. Tingang Nelise dance is one of the dances that has many variations of the Karang Sapeq dances, which is the embodiment of Tingang Nelise or the result of a change in name which was originally known as the Tingang Mate Dance, but because it gives less meaning and also because the movement is more accurately called Nelise (decorated).This research will explore the form and structure of the presentation of the Tingang Nelise dance with a choreography and structure approach. The choreography approach looks at themes, dancers, movements, dress and make-up, properties, and music accompaniment. While the structural approach of the Tingang Nelise dance is seen from the structural analysis of dance in the language analysis which analyzes from the smallest movement. Starting from the elements of movement, motives movement, phrases movement, sentences and group movement.The results of the analysis conclude that the Tingang Nelise Dance has a characteristic that can be seen from the motives of the movement which are dominated by foot and hand movements. Structurally, the Tingang Nelise dance is divided into 4 groups, and has 7 characteristic motive movement, namely the Ngaset that jumps to the right and left in a squatting position. The other motives are Nyebeb, Nyegung, Nyebib, Lemako, Nyelut, and Nelise.

\section{Keywords: Tingang Nelise, Dayak Bahau Busang, Long Gelaat}




\section{PENDAHULUAN}

Long Gelaat adalah satu dari banyak sub etnik Dayak yang ada di Kalimantan Timur, yang merupakan sub dari Dayak Apo Kayan. Dayak Long Gelaat sendiri terbagi lagi dalam sub yang lebih kecil dan memiliki dialek yang berbeda, yaitu Long Way, Wehie, Nehes Lieh Bieng, Ga'ai, dan masih ada lagi. Masyarakat Dayak Long Gelaat sebagian besar tinggal di sepanjang sungai Mahakam (Mekam) terutama di daerah kabupaten Kutai Barat, dan beberapa kelompok di bagian utara Kalimantan Timur.

Sebelum tinggal di daerah sungai Mahakam, suku Long Gelaat bermukim di Apo Kayan bersama-sama dengan kelompok suku yang lain. Apo Kayan adalah daerah dataran tinggi yang terletak di Kabupaten Malinau. Pada abad ke-17 terjadi perpindahan dalam kelompok besar ke arah Barat. Dalam perjalanan kelompok ini terbagi menjadi dua pada peristiwa Mutat Ji'it. Akibatnya kelompok pertama meneruskan perjalanan ke Barat dan kelompok kedua mengambil jalan memutar dan akhirnya ke arah Selatan.

Kelompok yang ke arah Barat akhirnya menetap di Kapuas bagian hulu yaitu di daerah Mendalam, Kalimantan Barat sehingga disebut Kayan Mendalam. Sedangkan kelompok yang ke Selatan akhirnya menetap di Mahakam, yaitu mulai dari ulu sungai Mahakam sampai bagian tengah, di daerah Tering. Sekarang termasuk dalam wilayah kabupaten Kutai Barat, Kalimantan Timur, sehingga disebut juga Kayan Mekam. Nama-nama dari anak suku Dayak Bahau terbagi 26 suku kecil-kecil dari ulu sungai sampai ilir antara lain ada 26 suku. Tari Tingang Nelise adalah tarian dari suku Dayak Bahau Busang Sub Suku Long Gelaat, bagian Ulu Mahakam, Kalimantan Timur. Tari Tingang Nelise adalah salah satu tarian yang memiliki banyak variasi dari tarian yang biasa disebut Karang Sapeq. Tari Tingang Nelise adalah tari yang merupakan nama baru dari tarian yang telah lama berkembang di seluruh suku Kayan (Bahau) yang ada di wilayah Mahakam Ulu, yaitu Tari Tingang Mate.

Penyesuaian nama dari Tingang Mate menjadi Tingang Nalise telah dibicarakan lama oleh Kepala Adat dan seluruh suku Kayan (Bahau) sejak tahun 1990, dan pada tahun 1995 disepakati secara bersama-sama oleh seluruh Lembaga Adat untuk mengubah Tingang Mate menjadi Tari Tingang Nalise. Perubahan nama ini berkait dengan beberapa alasan. Tingang Mate berarti "enggang mati", sehingga merupakan sesuatu yang janggal karena sesuatu yang mati tidak dapat menari. Jadi diubahlah Tingang Mate menjadi Tingang Nelise karena bermakna lebih positif. Dalam hal itu juga tariannya lebih hidup dengan nama Tingang Nelise dan lebih bisa dijelaskan daripada nama Tingang Mate. 
Perubahan nama tarian ini menjadi Tingang Nelise dirasa lebih tepat karena gerakannya lebih kepada Nelise (berhias) atau burung Enggang yang sedang merapikan bulunya, memperindah serta mempercantik dirinya. Selain itu, perubahan nama ini dimaksudkan juga untuk membalikkan reprensentasi tersebut menjadi simbolisasi kebangkitan dan harapan supaya bisa menjaga kelestarian dari burung Enggang. ${ }^{1}$ Akan tetapi tarian ini masih merupakan hasil perkembangan dari gerak Tari Tingang Mate yakni gerakan Enggang yang terkena tembakan dari sumpit yang sudah diberi racun ${ }^{2}$.

Pada proses penciptaan tari Tingang Nelise ini dikarenakan adanya perbedaan pandangan tentang tari Tingang Mate itu sendiri yang menjadi masalah oleh tokoh-tokoh adat sehingga terciptanya proses perkembangan nama baru yang menjadi tari Tingang Nelise. Dalam penelitian ini, pokok persoalan yang paling menarik adalah pada proses perubahan nama dari Tingang Mate menjadi tari Tingang Nelise dan proses penentuan nama pada setiap motif gerak dalam struktur tari yang telah dibuat secara bersama oleh para leluhur, agar diketahui oleh masyarakat yang ada di daerah

${ }^{1}$ Wawancara dengan Adrianus Liah Blawing (36 tahun), selaku Ketua Sanggar Seni Apo Lagaan, Jam 12:40, Tanggal: 30 Maret 2019, dilakukan di rumah Narasumber, di jl. Siti Aisyah diizinkan untuk dikutip. maupun masyarakat luas. Hal ini dikarenakan kaum muda yang ada di daerah tersebut hanya bisa menarikannya saja tetapi tidak mengetahui nama dari setiap motif gerak yang ditarikan. Penelitian ini juga ingin mengetahui bagaimana para nenek moyang membuat nama dari setiap motif geraknya, apa yang menjadi dasar perubahan nama dilihat dari dari bentuk dan struktur dalam tarian ini.

Masyarakat penonton atau audience adalah masyarakat yang merenungkan atau mengamati karya itu. ${ }^{3}$ Masyarakat suku Dayak Bahau Busang Sub Suku Long Gelaat biasa melakukan tarian Tingang Nelise pada saat acara apa saja (tidak ada ketentuan khusus), Masyarakat suku Dayak Bahau Busang Sub Suku Long Gelaat bisa melihat tarian ini pada saat acara di umaaq aruq yang berkaitan dengan upacara daur kehidupan, misalnya seperti: Nemlaai, acara adat anak, pernikahan dan dangai.

Gerak-gerak dari Tari Tingang Nelise sebenarnya menggambarkan keseharian burung Enggang pada pagi hari yang di mana ada sebuah bentuk dari kegiatan burung Enggang yang tiap hari membersihkan bulu-bulunya, mereka meloncat-loncat dan mengeringkan

2 Wawancara dengan Arbiyansyach Jueng (38 tahun), Jam 11:27, Tanggal: 9 Mei 2018, di rumah Narasumber, di jl. Siti Aisyah diizinkan untuk dikutip.

${ }^{3}$ Y. Sumandiyo Hadi, 2014. Koreografi: Bentuk, Teknik-Isi, Yogyakarta: Cipta Media. p. 3 
bulu-bulu mereka dari embun pagi serta mempercantikkan diri, sehingga dibuatlah dalam bentuk tarian dengan makna yang ditentukan dari keseharian burung Enggang berdasarkan dari sikap-sikap burung Enggang, sejarah, tipe tubuh yang dimiliki dengan menggerakkan anggota tubuh yang diperlukan, karena dalam tarian ini iringan musik yang mengiringi temponya lambat dengan ketukan musiknya yang monoton tidak berubah-ubah.

\section{PEMBAHASAN}

\section{A. Sejarah Tari Tingang Nelise}

Tari Tingang Nelise adalah judul tari yang merupakan nama baru dari tarian yang telah lama berkembang di seluruh suku Kayan (Bahau) yang ada di wilayah Mahakam Ulu, yaitu Tari Tingang Mate. Penyesuaian nama dari Tingang Mate menjadi Tingang Nelise telah dibicarakan lama oleh Kepala Adat dan seluruh suku Kayan (Bahau) sejak tahun 1990 dan pada tahun 1995 disepakati secara bersamasama oleh seluruh Lembaga Adat untuk mengubah Tingang Mate menjadi Tari Tingang Nelise. Perubahan nama ini berkait dengan beberapa alasan. Tingang Mate berarti "Enggang mati", sehingga merupakan sesuatu yang janggal karena sesuatu yang mati tidak dapat menari.
B. Bentuk Penyajian Tari Tingang Nelise

\section{Tema Tari Tingang Nelise}

Suatu gambaran asli dari rupa burung Enggang yang kemudian distilisasikan masyarakat Long Gelaat untuk menjadi suatu bentuk penyajian tari yaitu Tingang Nelise. Tarian ini menggambarkan keindahan, kecantikan, dan keanggunan burung Enggang yang digambarkan dengan gerak tangan dan kaki yang terangkum dalam 7 motif gerak tari yang merupakan gerak-gerik burung Enggang yang sudah distilisasi atau diperhalus oleh masyarakat Long Gelaat.

Tari hiburan atau rakyat adalah tarian yang bertujuan untuk menghibur para penonton, sekaligus untuk mulai melestarikan budaya yang ada sehingga tidak mudah untuk dilupakan, dan memiliki berbagai macam bentuk tarian yang sudah menjadi dasar untuk mengungkapkan suatu keindahan yang ada di dalam tari tersebut dapat tersampaikan ke dalam masing-masing hati penonton.

Tari Tingang Nelise ditarikan secara berpasangan oleh penari laki-laki dan perempuan, sehingga bisa disebut juga tari pergaulan. Banyak gerak-gerak yang dilakukan saling berhadapan dengan pola yang berbeda antara gerak laki-laki dan perempuan, sehingga penari harus fokus ketika menari. Gerak yang paling spesifik adalah gerak Ngaset dan Nelise 


\section{JOGED}

ISSN: $1858-3989$

yaitu gerak melompat untuk berdekatan dan saling berhadapan. Pada saat itu penari laki-laki akan berteriak "iwww....". Hal ini membuat tarian ini semakin menarik perhatian dan membuat kaget masyarakat yang menontonnya.

\section{Penari}

Tarian ini juga merupakan kesenian hiburan rakyat yang ditarikan secara berkelompok yang zaman dahulu tarian ini hanya ditarikan oleh perempuan. Akan tetapi zaman kini tarian ini juga dapat ditarikan oleh laki-laki. Dalam hal ini tidak ada kelompok khusus untuk menarikan tarian ini dan tidak dapat ditentukan jumlah penarinya. Dalam tari Tingang Nelise ini yang biasa di tampilkan dalam panggung pertunjukan berjumlah 7-10 orang penari, akan tetapi dibagi dalam 4-5 penari perempuan dan 3-5 penari laki-laki dalam tarian yang sudah dikreasikan ke dalam bentuk panggung pertunjukan.

\section{Gerak Tari}

Dalam pertunjukan tarian Tingang Nelise gerakan yang paling dominan adalah gerak kaki. Tari Tingang Nelise adalah salah satu dari tarian Karang Sapeq yang memiliki gerak dasar yang sama seperti: kaki melangkah dan menghentak. Motif gerak yang paling mendasar dari tari Tingang Nelise adalah gerakan yang lemah gemulai dilihat dari gerak disebut Nelise memiliki gerakan dengan posisi
UR PENYAJIAN TARI TINGANG NELISE PADA SUKU DAYAK BAHAU BUSANG SUB SUKU LONG GELAAT DI ULU MAHAKAM jongkok dengan posisi tangan kanan di depan, tangan kiri berada di belakang dengan gerak tangan naik turun secara perlahan-lahan, serta gerak Ngaset yang meloncat-loncat ke kanan dan kiri sehingga perempuan dan laki-laki mempunyai keseimbangan tubuh dan tidak ada perbedaan antara gerak karena ada nuansa yang cukup gembira dan energik dalam tarian ini.

\section{Properti}

Masyarakat Mahakam Ulu khususnya wanita selalu menggunakan properti yaitu kirap yang digunakan untuk menambah keanggunan dari seorang wanita yang diselipkan pada jari manis dan berbedala halnya dengan suku dari dayak yang lainnya. Dari hal ini juga yang membedakan masyarakat ulu Mahakam yaitu dilihat dari 1 pasang kirap hanya berisi 8 yang artinya hitungan sakral bagi masyarakat Mahakam Ulu dan hitungan ini merupakan kesungguhan hati.

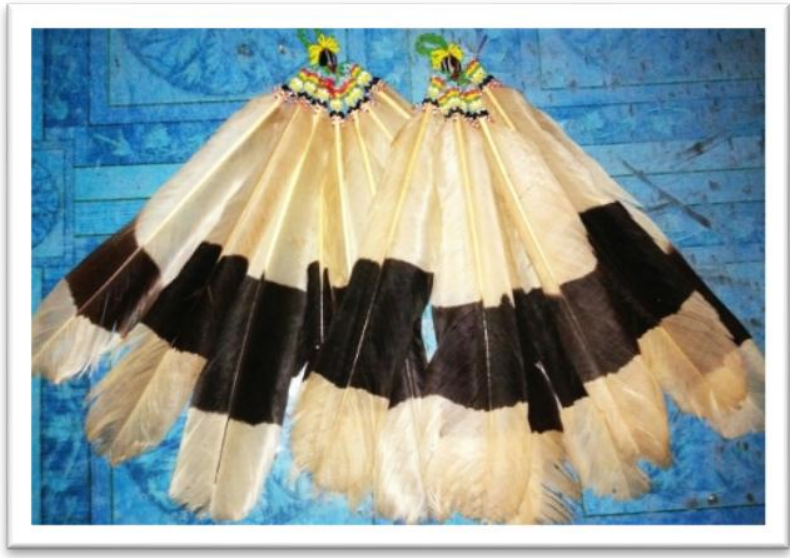

Gambar 1. Bentuk Kirap

(Foto: Katarina Devung, 2020) 


\section{Tempat dan Waktu Pertunjukan}

Tempat dan waktu pertunjukan juga dapat menjadi simbol dari makna suatu karya tari yang akan di tampilkan. Masyarakat suku Dayak Bahau Busang Sub Suku Long Gelaat biasa melakukan tarian Tingang Nelise pada saat acara apa saja (tidak ada ketentuan khusus) kepada masyarakat. Tarian ini juga dilakukan pada acara-acara besar seperti Nemlaai, Hudoq, dan lain-lain.

Tempat pertunjukannya juga bisa diadakan di lapangan besar dan bisa di panggung pertunjukan seperti proscenium stage, teater arena untuk mengisi acara, juga dipadukan dengan berbagai macam bentuk tarian dan lain sebagainya. Dalam hal ini waktu pertunjukan yang sudah ditampilkan di panggung pertunjukan berdurasi 5-6 menit karena apa durasi panjang dikarenakan sudah digabungkan dan dikreasikan dengan tarian yang lain, sedangkan jika masih diadakan di lapangan besar berdurasi 2-3 menit dikarenakan jika berdurasi lama akan mempengaruhi reaksi penonton.

\section{Tata Rias dan Busana}

Tata Rias pada wajah mendukung ekspresi yang akan dibangun oleh penari. Tari Tingang Nelise tidak menggunakan make up karakter, tetapi hanya make up korektif dengan tampil secara sederhana dengan menggunakan apa saja kebutuhan yang diperlukan. Rias yang digunakan juga dapat memberikan suatu kesan agar kita dapat memahami tempat dan karakter yang ingin disampaikan

Dalam hal ini juga wajah penari dihias secara natural untuk memperkuat kesan masyarakat pedalaman. Ada beberapa dari kelengkapan kostum yang digunakan dalam tarian ini misalnya Tap ajang dan layah. Nama kostum dari Tap ajang dan Layah antara lain:

a. Rok (ta'ah), baju (basung), kalung (inuq ujung), topi (lavung ube), teqsak (aksesoris yang dipakai di pinggang), isang (aksesoris yang digantungkan ke telinga kanan dan kiri sebagai pengganti anting), tajo (kirap yang diletakkan di samping kepala kiri dan kanan pada saat dipakai sesudah memakai lavung ube), telbeq (aksesoris di bagian leher yang diikatkan ke belakang setelah memakai baju), gelang, kirap.

b. Kostum Layah ini juga lebih sederhana tidak menggunakan manik, kostum ini lebih terlihat sederhana karena tidak ada manik namun banyak sekali makna yang terkandung dan ukiran dari kostum Layah.

7. Musik Iringan

Alat musik sapeq adalah alat musik petik tradisional yang bebeda jenis dari sapeq yang banyak dipopulerkan atau dikembangkan oleh para pelaku seni baik yang berasal dari sanggar-sanggar seni maupun lingkungan 
akademisi. Musik yang mengiringi tari Tingang Nelise adalah Sapeq Karaang atau biasa disebut Sapeq Ting Duaq yang nadanya sudah diatur, karena dalam tarian ini iringan musik yang mengiringi temponya sedang dengan ketukan musiknya yang diulang-ulang terus menerus sehingga musiknya monoton tidak berubah-ubah. Sapeq Karaang atau yang biasa disebut sapeq ting duaq masih cukup asing terutama di kalangan masyarakat umum. Sapeq Karaang sebagai salah satu ragam jenis kekayaan seni musik dari suku Dayak ${ }^{4}$.

\section{Pola Lantai}

Dalam tari Tingang Nelise ini penari membentuk pola lurus dan pola lingkaran atau menari secara bersama dengan mulai membentuk pola lingkaran. Tari Tingang Nelise biasanya dilakukan oleh laki-laki dan wanita, dengan barisan yang teratur dalam satu lingkaran. Tarian ini juga merupakan salah satu tarian yang interaktif dengan mengajak penonton secara perlahan-lahan untuk masuk ke dalam lingkaran supaya bisa ikut serta dalam menari. Siapapun boleh bergabung dalam tarian tersebut, tidak memandang usia, dari yang muda sampai tua dapat bergabung dalam satu lingkaran tersebut.

${ }^{4}$ Dikutip dari web: https://damaibumi.com/2017/05/03/sape-karaangbagian-i/, diakses pada tanggal: 4 Oktober 2018.

\section{Struktur Tari Tingang Nelise}

Diawali dari memandang tari secara keseluruhan, struktur tari dapat dipilah ke dalam gugus, kalimat, frase, dan motif. Gugus gerak dalam tari disetarakan dengan paragraf dalam kalimat yang dapat dipilah berdasarkan iringan, adegan, ataupun cerita. Gugus gerak akan diperkecil menjadi kalimat gerak, frase, dan motif. ${ }^{5}$ Bentuk dan struktur merupakan dua hal yang tidak dapat terpisahkan, bentuk merupakan organisasi secara keseluruhan dari hubungan antar karakteristik dalam tari, sedangkan struktur adalah rangkaian atau susunan dari gerak yang telah diciptakan untuk menjadi kesatuan yang utuh dan tertata rapi. Struktur gerak tari merupakan rangkaian atau susunan dari gerak-gerak tari yang tersusun menjadi satu, selanjutnya yang dimaksud struktur tari adalah suatu organisasi keseluruhan dari hubungan antara karakteristik di dalam tari. ${ }^{6}$

1. Pembagian Struktur Tari Tingang Nelise

Dalam tarian ini ada susunan tarian yang sudah dibuat atau disusun dengan pola gerak dengan ketentuan khusus yang dalam suatu susunan yang beraturan dari gerak awal sampai

${ }^{5}$ Lihat Rina Martiara, Budi Astuti, 2018, Analisis Struktural Sebuah Metode Penelitian Tari .Yogyakarta: Badan Penerbit ISI Yogyakarta. p. 156 ${ }^{6}$ Dikutip dari web lib.unnes.ac.id, 2015, diakses pada tanggal: 30 Mei 2020. 
akhir. Struktur Tari Tingang Nelise berdasarkan pada pola-pola gerak, pola iringan, serta adegan terbagi menjadi 3 bagian yaitu bagian awal, bagian isi, dan bagian akhir.

Jika dicermati berdasarkan pola iringan, maka struktur tari Tingang Nalise terdiri dari 4 bagian yaitu introduksi, adegan pertama, adegan kedua, dan ending (akhir). Sesungguhnya pola ini setara dengan pembagian yang didasarkan pola gerak, yaitu bagian awal, bagian isi dan bagian akhir. Hanya saja musik iringan tari Tingang Nelise selalu diawali oleh musik iringan sebagai introduksi.

\section{a.Introduksi}

Sebelum tarian dimulai, akan di awali dengan iringan musik yang biasa digunakan dalam tari Tingang Nelise ini yang disebut sapeq karang atau sapeq ting duaq yang menggunakan nada pentatonik dengan alunan musiknya yang monoton. Dari situlah tarian itu sudah terlihat dengan jelas. Setelah itu tidak lama kemudian penari mulai masuk untuk menggerakkan seluruh anggota tubuh untuk saling berinteraksi dengan pola irama musiknya yang sedang, karena dalam tarian ini musik iringan yang mengiringi tarian ini menggunakan tempo sedang dengan ketukan musiknya yang diulang-ulang terus menerus sehingga musiknya disebut monoton tidak berubah-ubah. Dari sinilah para penari mulai masuk untuk membentuk sebuah lingkaran dari lingkaran sampai menjadi lingkaran besar.

\section{b. Adegan Pertama}

Tingang Nelise ini dimulai dengan gerakan yang lemah gemulai, dari situlah mulai masuklah para penari menirukan gerak burung Enggang untuk mulai menunjukkan motifmotif gerak tersebut. Dengan membuka kedua tangan selebar bahu dihiasi dengan properti kirap yang diselipkan di jari manis, kemudian kedua tangan ini secara bersamaan mengayunkan tangan turun naik secara perlahan dan menghentakkan kaki ke lantai layaknya menirukan seekor burung Enggang yang hinggap dari ke dahan.

\section{c. Adegan Kedua}

Dilihat dari perbedaan geraknya yang ada di adegan pertama menjadi suatu pembagian dalam tari Tingang Nelise ini adalah yang di mana berada di inti tarian atau bagian tengah cerita. Dengan gerakan Lemako, Nyelut, Ngaset, yang menggambarkan bagaimana gerakan dari seekor burung Enggang dengan gerak melangkah maju, mundur, dan meloncat.

Dalam hal peneliti juga melihat bagaimana keunikan gerak tari ini adalah gerak yang bervariasi namun tetap berada di pakem geraknya dengan menunjukkan gerak yang bersifat lincah, dinamis, ekspresif dan berkesinambungan. Dengan adanya gerak ini 
membuat masyarakat akan bisa lebih terbuka lagi pola pikirnya untuk bisa menerima bagaimana perubahan dari masa ke sama yang kian berkembang untuk bisa membuat tarian ini akan lebih berkembang dengan pola-pola yang baru tapi tetap berada di tradisi tersebut.

\section{c. Ending (Akhir)}

Gerakan Nelise yang menuju ke klimaks ini akan diawali lagi dengan gerak nyebeb mulai diulang kembali seperti awal di mana burung Enggang mulai berdiri tegak mengepakkan bulu burung Enggang dengan keindahannya. Dalam bagian ini termasuk klimaks di mana gerakan Nelise ini menggambarkan bagaimana lelahnya seekor burung Enggang yang terkena racun sumpit dan racun yang sudah berada di tubuhnya mulai bereaksi sehingga membuat Enggang mulai kelelahan. Dilihat dari geraknya yang telah distilisasikan dengan mengayunkan kedua tangan ke samping kanan dan kiri. Tari ini akan diakhiri dengan musik yang perlahan-lahan mulai turun dengan temponya yang lambat dan para penari mulai meninggalkan panggung pertunjukan dengan alunan musik yang secara perlahan-lahan mulai berhenti dan para penari mulai ke luar dengan tempo musiknya yang lambat.

\section{Motif Tari Tingang Nelise}

Motif adalah satuan terkecil dari sebuah struktur tari yang mempunyai ciri-ciri sebagai berikut. Ada awal dan akhir dari gerak dapat diketahui, gerak tersebut dapat diulang dan melibatkan anggota tubuh secara keseluruhan. Dalam tarian ini merupakan adanya kesamaan hubungan yang terkait dengan menyerupai tarian tradisi yang menjadi satu kaitan dengan yang lain. Dalam tari Tingang Nelise ini memiliki beberapa gerakan dasar, ada 7 Motif dari Tari Tingang Nelise adalah: Nyebeb, Nyegung, Nyebib, Lemako, Nyelut, Ngaset dan Nelise.

\section{Gaya Tari Tingang Nelise}

Gaya adalah ciri spesifik dari sebuah tari yang membedakan tarian tersebut dengan tari lainnya. Gaya adalah ciri khas, sesuatu yang melekat di dalam sebuah pertunjukan sehingga siapapun yang melihat sebuah pertunjukan akan mengatakan bahwa pertunjukan ini adalah Tari Tingang Nelise yang berasal dari Dayak sub suku Long Gelaat. Tari Tingang Nelise mengisahkan bagaimana burung Enggang ini bisa bertahan hidup untuk waktu yang lama. Dilihat dari cara berpindah-pindah tempat dengan mengepakkan kedua sayapnya dengan memperlihatkan keindahan dari sayap sampai ekornya. Kisah perjuangan burung Enggang yang hidup dengan mengandalkan alam sangat berkesan kuat di dalam masyarakat Dayak, 
sehingga mereka mengidentikkan diri mereka sebagaimana burung Enggang.

Struktur tari Tingang Nelise ini terdapat 4 bagian, tapi terbagi dalam 3 bagian yang penting termasuk dalam gerak utama atau inti tarian yang dapat di lihat dalam 3 adegan yang di deskripsikan di atas, juga ditambahkan dengan introduksi di bagian awal untuk membuka tarian tersebut hingga menjadi suatu pola iringan yang menjadikan 4 bagian pola yang terpecah dan dapat kita lihat di atas. Selain berdasarkan pola gerak, keempat struktur tari ini didasarkan pada adegan yang menceritakan perjalanan mengenai suku Dayak untuk menjaga keindahan dari burung Enggang sehingga tidak punah. Gerak Tingang Nelise ini juga memiliki sebuah makna yang didapat dari meniru gerakan burung Enggang yang sekarat. Namun dalam gerak-gerak Tingang Mate yang menggambarkan bagaimana proses Enggang yang sekarat, sesungguhnya mengandung nilai keperkasaan seorang laki-laki Dayak.

Dari gerak-gerak Enggang tersebut kemudian diubah menjadi gerak Enggang yang menggambarkan kecantikan, keindahan, dan keanggunan Enggang. Juga menggambarkan bagaimana Enggang berhias untuk menunjukkan keindahan bulu-bulu mereka. Dari situlah perubahan nama itu terjadi yang dulunya Tingang Mate menjadi Tingang Nelise dikarenakan untuk bisa mengekspresikan kecantikan Enggang yang juga merupakan kecantikan Dayak. Dalam tari Tingang Nelise ini ada motif gerak yang dapat kita lihat dari gerak yang dominan sering menggunakan gerakan kaki dan tangan, dikarenakan gerakan kaki itu mencirikan bagaimana Karang Sapeq yang terlihat dari ciri khas gerakannya dengan gerak yang ritmis, dinamis dari hentakan kaki dan gerak melangkah yang sudah turun temurun diwariskan.

Ciri yang menonjol lainnya pada Tari Tingang Nelise adalah pada instrumen pengiring, yang bernama Sapeq karaang. Sapeg karaang adalah alat musik petik dua yang dimainkan oleh satu orang, karena dalam tarian ini iringan musik yang mengiringi temponya sedang dengan ketukan musiknya yang diulang-ulang terus menerus sehingga musiknya monoton tidak berubah-ubah.

\section{PENUTUP}

Berdasarkan dari hasil penelitian dan pembahasan, maka peneliti dapat mengambil kesimpulan sebagai berikut:

Tari Tingang Nelise merupakan bagian gerak yang selalu terlihat gembira, energik dengan mengekspresikan 7 motif gerak yang nampak dengan memperlihatkan bagaimana gerakannya terlihat dari semangat kelembutan. Tari ini merupakan bagian dari tari Tingang Nelise yang mengekspresikan bagaimana gerak 
yang terbentuk dari elemen-elemen tubuh yang membentuk suatu unsur gerak dari yang terkecil sampai terbesar dari sebuah tari yang saling berkaitan sehingga dapat menjadi bentuk tari. Dilihat dari Tari Tingang Nelise yang meliputi satuan terkecil yang disebut dengan motif gerak yang secara langsung berada dalam satuan yang terbesar yaitu frase gerak. Frase gerak juga terikat oleh bagian yang lebih besar yaitu kalimat gerak hingga membentuk menjadi suatu gugus gerak yang kemudian terhimpun menjadi satu kesatuan yang utuh disebut dengan analisis struktural yang terlihat sangat identik dari semangat geraknya yang memperlihatkan kelemah kelembutan wanita tapi tidak harus wanita juga yang menarikan tari Tingang Nelise laki-laki juga bisa menarikan tarian ini.

Setelah di identifikasikan tari Tingang Nelise terdiri dari tiga puluh tiga motif gerak, sebelas frase gerak, enam kalimat gerak dan tiga gugus gerak yang menjadi satu bentuk tarian yang kemudian di ulang lagi tarian ini kembali ke bentuk awal sehingga menjadi suatu bentuk dan struktur tarian yang tumpang tindih dan silih berganti.

Dalam tarian ini juga sangat penting untuk dikemukakan atau diperlihatkan agar masyarakat mengetahui mengenai tradisi yang ada di dalam suku tersebut mungkin salah satunya ada sebagian dari masyarakat yang mengetahui yaitu pengurus Adat mengenai penulisan ini.

\section{DAFTAR SUMBER ACUAN}

\section{A. Sumber Tertulis}

Hadi, Y Sumandiyo. 2014. Koreografi: BentukTeknik-Isi. Yogyakarta: Cipta Media.

Simatupang, Lono. 2013. Pergelaran Sebuah Mozaik Penelitian Seni Budaya. Yogyakarta: Jalasutra Anggota IKAPI.

Martiara, Rina dan Budi Astuti. 2018. Analisis Struktural Sebuah Metode Penelitian Tari .Yogyakarta: Badan Penerbit ISI Yogyakarta.

\section{B. Sumber Lisan}

Pemberdayaan Komunitas Adat, Lembaga

Adat dan Hak Ulayat Oleh: B. Blawing Belareq 2018, diizinkan untuk dikutip.

1. Nama : Arbiyansyach Jueng, selaku pemain musik

$$
\begin{aligned}
& \text { di Sanggar Seni Apo } \\
& \text { Lagaan }
\end{aligned}
$$

Umur : $\quad$ :38 Tahun

Tempat : di kediaman B.Blawing Belareq, Jl. Siti Aisyah gang. 4c Samarinda 
BENTUK DAN STRUKTUR PENYAJIAN TARI TINGANG NELISE

$$
\text { Tanggal : } 9 \text { Mei 2018, Pukul }
$$

14:05 WITA.

2. Nama : Adrianus Liah

Belawing

$\begin{array}{ll}\text { Umur } & : 36 \text { Tahun } \\ \text { Tempat } & : \text { ada Dua tempat } \\ & \text { wawancara, wawancara } \\ & \text { pertama di kediaman B. } \\ & \text { Blawing Belareq, Jl. Siti } \\ & \text { Aisyah gang. } 4 \mathrm{c} \\ & \text { Samarinda }\end{array}$

Tanggal : Wawancara pertama:

30 Maret 2019, pukul 12:22 WITA.
Wawancara kedua: 6
Januari 2020, pukul
17:07 WITA.

\section{Sumber Webtografi}

https://damaibumi.com/2017/05/03/sape-

karaang-bagian-i/

lib.unnes.ac.id , 2015 